Article

\title{
Free-Standing Reduced Graphene Oxide/Carbon Nanotube Paper for Flexible Sodium-Ion Battery Applications
}

\author{
Yong Hao ${ }^{1(1)}$ and Chunlei Wang ${ }^{1,2, *}$ \\ 1 Department of Mechanical and Materials Engineering, Florida International University, 10555 W. Flagler St., \\ Miami, FL 33174, USA; yhao004@fiu.edu \\ 2 Center for the Study of Matter at Extreme Conditions, Florida International University, University Park, \\ Miami, FL 33199, USA \\ * Correspondence: wangc@fiu.edu; Tel.: +1-305-348-1217
}

Received: 21 December 2019; Accepted: 23 February 2020; Published: 24 February 2020

check for updates

\begin{abstract}
We propose a flexible, binder-free and free-standing carbonaceous paper fabricated via electrostatic spray deposition using reduced graphene oxide/carbon nanotube (rGO/CNT) as a promising electrode material for flexible sodium-ion batteries (NIBs). The as-prepared rGO/CNT paper exhibits a three-dimensional (3D) layered structure by employing rGO as conductive frameworks to provide sodium-storage active sites and CNT as spacer to increase rGO interlayer distance and benefit the diffusion kinetics of sodium ions. Consequently, the $\mathrm{rGO} / \mathrm{CNT}$ paper delivers an enhanced sodium ion storage capacity of $166.8 \mathrm{mAh} \mathrm{g}^{-1}$ at $50 \mathrm{~mA} \mathrm{~g}^{-1}$, retaining an average capacity of $101.4 \mathrm{mAh} \mathrm{g}^{-1}$ when current density sets back $100 \mathrm{~mA} \mathrm{~g}^{-1}$ after cycling at various current rates. An average capacity of $50 \mathrm{mAh} \mathrm{g}^{-1}$ at $200 \mathrm{~mA} \mathrm{~g}^{-1}$ was stabilized when cycling up to 300 cycles. The well-maintained electrochemical performance of free-standing rGO/CNT paper is due to the well-established hybrid 3D nanostructures, which demonstrates our carbon based material fabricated by a facile approach can be applied as one of the high-performance and low-cost electrode materials for applications in flexible energy storage devices.
\end{abstract}

Keywords: reduced graphene oxide/carbon nanotube (rGO/CNT); free-standing; anode; sodium-ion batteries; flexible

\section{Introduction}

Although lithium-ion batteries have dominated the global electrochemical energy storage market in portable electronics for the past three decades, large scale applications such as electric vehicles and renewable energy integrations call for alternatives beyond Li-ion energy storage systems [1,2]. Sodium-ion batteries (NIBs) have drawn enormous attention owing to the inexhaustible Na resources and the similar electrochemical reaction mechanism to lithium metal [3-5]. However, there are challenges that need to be tackled before NIBs can be commercialized. One of the challenges is the relatively large size of $\mathrm{Na}$ ion $(0.102 \mathrm{~nm}$ vs. $\mathrm{Li}$ ion: $0.059 \mathrm{~nm})$, which could potentially reduce the efficiency of $\mathrm{Na}$ ion intercalation and de-intercalation if electrode materials do not exhibit favorable structures $[6,7]$. Recently various studies have been conducted to identify advanced electrodes with efficient kinetics and high storage capacity for NIBs to improve their electrochemical performance [8-13]. Carbonaceous materials with advantages of low-cost, eco-friendliness and high conductivity attract great interest as electrode material candidates for NIBs. Various carbonaceous materials including porous carbon [14,15], hard carbon [16], carbon nanofibers [17,18], graphene [7,19] and carbon nanotubes $[20,21]$ have been studied and found to facilitate the sothiation/desothiation process of $\mathrm{Na}^{+}$into/from the active electrode hosts owing to the large interlayer distance and/or disordered 
structure. Among them, graphene and CNT are considered as two promising candidates in energy storage systems owing to their unique dimensional structures and beneficial intrinsic properties such as chemical stability, low weight, high mechanical flexibility and excellent electrical conductivity [22,23].

In addition to the electrode material itself, recently, flexible and bendable electronic devices have been urgently required. In order to power these devices, there is a persistent need to build multifunctional energy storage systems that are equally flexible and bendable under deformation while maintaining their electrochemical function [24]. Recently, a lot of research efforts have been focused on designing free-standing and binder-free electrodes with excellent flexibility [25]. For these types of electrodes, the elimination of polymer binder and conductive additive which are the inactive electrode components could reduce the overall mass of the electrode and be beneficial for the improvement of energy density. This also benefits to avoid the detachment at the interface between metal foil current collector and the electrode during charge/discharge process, which is one of the major issues for the flexible batteries due to the bending or folding of the devices [26]. To make the electrode materials flexible while achieving high energy density, different synthesis methods have been used such as hydrothermal, solvothermal, vacuum filtration, electrospinning, etc. [25]. Compared with other methods, the electrospinning technique as a remarkably simple, versatile and controllable method, has been used to generate nanofiber-containing flexible fibrous mats with different composition and thickness [27]. A variety of free-standing carbon fiber anode materials fabricated by electrospinning have been investigated for NIBs [17,28-30]. To fabricate the carbon fibers, various polymer solutions are used as precursors to synthesize polymer fibers and followed by subsequent pyrolysis [22]. Free-standing graphene films or graphene-assisted composites have been fabricated by thermal or filtration methods $[7,11,31,32]$. However, when graphene is individually employed as anode for NIBs, graphene could only deliver a limited storage capacity due to strong preferential stacking orientation of compact graphene nanosheets in the conventionally filtrated graphene in which $\mathrm{Na}$ ions cannot sufficiently transport. Therefore, the strategies of heteroatom doping in carbonaceous materials or designing hybrid nanostructures containing graphene have been proposed to avoid the stacking of graphene nanosheets and enhance the overall electrochemical performance of NIBs $[33,34]$. An et al. demonstrated that fluorine and nitrogen co-doping on graphene could increase the structural defects and expand the interlayer distance, which improved electrochemical performance with a stable capacity of $203 \mathrm{mAh} \mathrm{g}^{-1}$ at $50 \mathrm{~mA} \mathrm{~g}^{-1}$ current density after 100 cycles [7]. Besides the doping method, Yan and his colleagues proposed sandwich-like nanocomposites assembled by employing porous carbon with a hierarchical structure on both surfaces of graphene to facilitate diffusion of $\mathrm{Na}$ ions. By designing this hybrid structure, the composite exhibited specific capacity of $400 \mathrm{mAh} \mathrm{g}^{-1}$ at current density rate of $50 \mathrm{~mA} \mathrm{~g}^{-1}$ in 100th cycle [14]. Liu et al. combined two strategies and prepared a carbonaceous hybrid material with sandwich-like nanostructure by using N-doped carbon coated on graphene sheet. The hybrid material exhibited a large distance of $0.36 \mathrm{~nm}$ between interlayers and exhibited a sodium electrochemical battery performance of $336 \mathrm{mAh} \mathrm{g}^{-1}$ at $30 \mathrm{~mA} \mathrm{~g}^{-1}$ after 200 cycles [6].

Similar to the electrospinning technique, electrostatic spray deposition (ESD) is an easily-operated and efficient technique to prepare binder-free electrodes for energy storage systems [35,36]. No subsequent heat treatment is needed since the decomposition and reaction directly occur before or after the as-prepared solution/suspension droplets arrive at the heated substrate [37]. Figure $1 \mathrm{a}, \mathrm{b}$ present a schematic illustration of ESD and an actual setup in the lab, respectively. The electrodes are fabricated as thin films with various morphologies and structures controlled by the ESD experimental parameters, taking the voltage, the flow rate, the substrate temperature for instance. Both dissolved precursors and suspensions are prepared to fabricate different types of oxides, sulfides, carbides, phosphates, carbonaceous materials by the ESD technique [38]. 
(a)

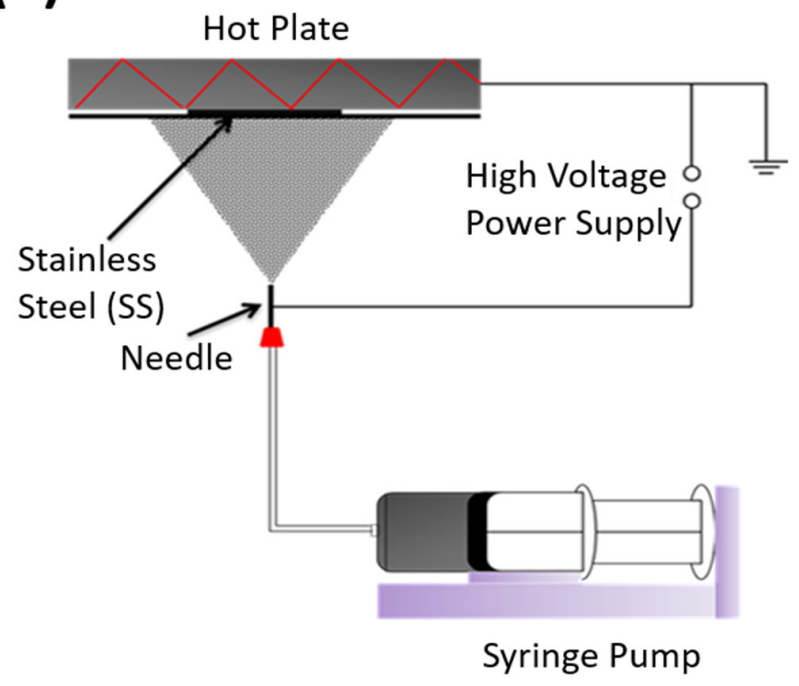

(c)

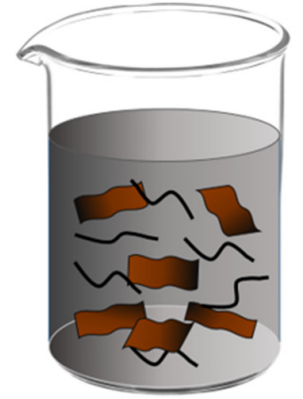

GO/CNT suspension (b)

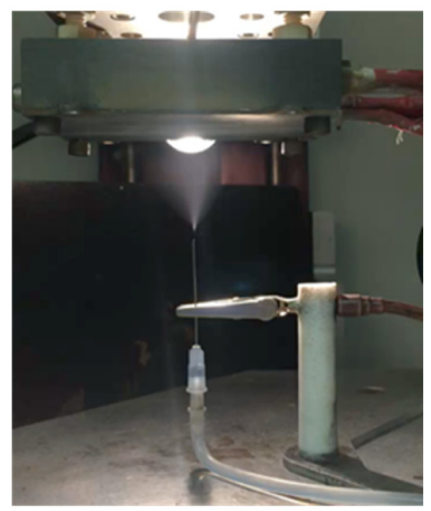

(d)

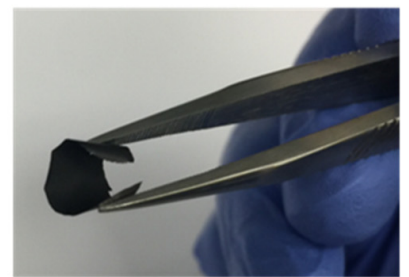

Figure 1. (a) Schematic illustration of ESD set-up that was used to fabricate rGO/CNT samples, Digital images of (b) shows actual ESD set-up, (c) Schematic of rGO/CNT fabrication and (d) a digital image of free-standing $\mathrm{rGO} / \mathrm{CNT}$ paper.

Our previous work has demonstrated that ESD-fabricated reduced graphene oxide/carbon nanotube (rGO/CNT) nanocomposite is a promising electrode candidate for both microsuper-capacitors and Li-ion capacitors $[39,40]$. In this work, we extend our investigation by using ESD to fabricate free-standing $\mathrm{rGO} / \mathrm{CNT}$ paper and electrochemically evaluating this material as an anode for NIBs. CNT is employed as a separator to eliminate the stacking phenomenon and expand the interlayer distance of rGO to optimize the Na ion's transportation pathway. Benefiting from hybrid structure, rGO/CNT paper as a free-standing and flexible anode for NIBs retains a recovered capacity of 101.4 $\mathrm{mAh} \mathrm{g}^{-1}$ at density rate of $100 \mathrm{~mA} \mathrm{~g}^{-1}$ after cycling at various rates.

\section{Experimental}

\subsection{Fabrication of Freestanding rGO/CNT Paper}

The raw single-layer GO powder and multi-walled carbon nanotubes (MWCNT, outer diameter: 8-15 nm, Length: 10-50 $\mu \mathrm{m}$ ) were purchased from Cheaptubes Inc. (Grafton, VT, USA). MWCNTs were first subjected to an acid treatment process to remove the metal catalyst residues and CNTs cut into small segments of $0.2-1 \mu \mathrm{m}$. To fabricate one piece of freestanding $\mathrm{rGO} / \mathrm{CNT}$ paper, $5.4 \mathrm{mg} \mathrm{GO}$ and $0.6 \mathrm{mg}$ MWCNT were first dispersed into $20 \mathrm{~mL} \mathrm{1,2-propanediol} \mathrm{and} \mathrm{with} \mathrm{sonicated} \mathrm{with} \mathrm{a} \mathrm{probe}$ for $1 \mathrm{~h}$ in an ice bath to form a precursor suspension with a concentration of $0.3 \mathrm{mg} \mathrm{mL} \mathrm{m}^{-1}$. Then a 
syringe pump was used to feed the precursor suspension at a rate of $3 \mathrm{~mL} \mathrm{~h}^{-1}$ into a stainless steel needle. A spacer used in coin cells with a diameter of $14 \mathrm{~mm}$ was taken as the substrate. It was placed on a hot plate beforehand and preheated to $300{ }^{\circ} \mathrm{C}$. A voltage of $5-6 \mathrm{kV}$ was applied between the needle and the stainless steel spacer substrate while the ESD process was carried out for $2 \mathrm{~h}$. After deposition, the free-standing rGO/CNT paper was detached from the substrate. The mass loading of the free-standing $\mathrm{rGO} / \mathrm{CNT}$ paper is about $0.6-0.8 \mathrm{mg}$. Figure $1 \mathrm{c}, \mathrm{d}$ show a schematic of the fabrication process and a digital image of as-prepared $\mathrm{rGO} / \mathrm{CNT}$ paper, respectively.

\subsection{Characterization and Electrochemical Measurements}

X-ray diffraction (XRD) patterns were generated to study the crystal structures of GO, rGO, CNT and rGO/CNT paper by using a D5000 X-ray Diffractometer (Siemens, Munich, Germany) with Cu K $\alpha$ radiation. The morphology of $\mathrm{rGO} / \mathrm{CNT}$ paper was studied using a FE6330 field-emission scanning electron microscope (FESEM, JEOL, Tokyo, Japan). Electrochemical measurements were performed with CR2032-type coin cells which were assembled in a glove box with inert argon gas. Coin cells were constructed with free-standing $\mathrm{rGO} / \mathrm{CNT}$ paper as well as two control samples $\mathrm{rGO}$ and CNT as working electrodes, $1 \mathrm{M} \mathrm{NaClO}_{4}$ in ethylene carbonate (EC) and dimethyl carbonate (DMC) as electrolyte (v/v 1:1), Celgard 2400 polypropylene film as a separator and Na foil as both reference and counter electrodes. Cyclic voltammetry (CV) was measured using a VMP3 system (Biologic, Seyssinet-Pariset, France) at a voltage window of $0.001-3 \mathrm{~V}\left(\mathrm{vs} . \mathrm{Na} / \mathrm{Na}^{+}\right.$) with a scan rate of $0.1 \mathrm{mV} \mathrm{s}^{-1}$. Galvanostatic charge/discharge profiles with cycle life and rate testing were conducted in the same voltage range as CV at different current densities using a BTS-610 battery tester (Neware, Shenzhen, China). Electrochemical impedance spectroscopy (EIS) was performed on Biologic VMP3 at a frequency range from $100 \mathrm{kHz}$ to $10 \mathrm{mHz}$ with an amplitude of $10 \mathrm{mV}$.

\section{Results and Discussion}

XRD results of GO, rGO, CNT and $\mathrm{rGO} / \mathrm{CNT}$ paper are plotted in Figure 2. The XRD curve of pristine GO exhibits a diffraction peak at $11.38^{\circ}$ corresponding to (001) plane with a value of $0.78 \mathrm{~nm}$ as d-spacing. The distinctive GO peak disappears in the rGO pattern, indicating a reduction of the layered GO sheets. The rGO pattern shows a broad peak centered at $24.34^{\circ}$ with a value of $0.37 \mathrm{~nm}$ as d-spacing, due to restoration of Van der Waals' bonding interactions between rGO sheets upon reduction [41]. The acid-treated CNT exhibits two distinctive peaks at $43.02^{\circ}$ and $26.3^{\circ}$ corresponding to (100) and (002) planes with of values of 0.21 and $0.34 \mathrm{~nm}$ as d-spacings, respectively. (002) peak in $\mathrm{rGO} / \mathrm{CNT}$ pattern slightly shifting position to lower $2 \theta$ of $25.22^{\circ}$ indicates the interaction between rGO and CNT [42]. This phenomenon is attributed to CNT embedded in between rGO sheets inducing the slightly larger spacing in rGO/CNT [43].

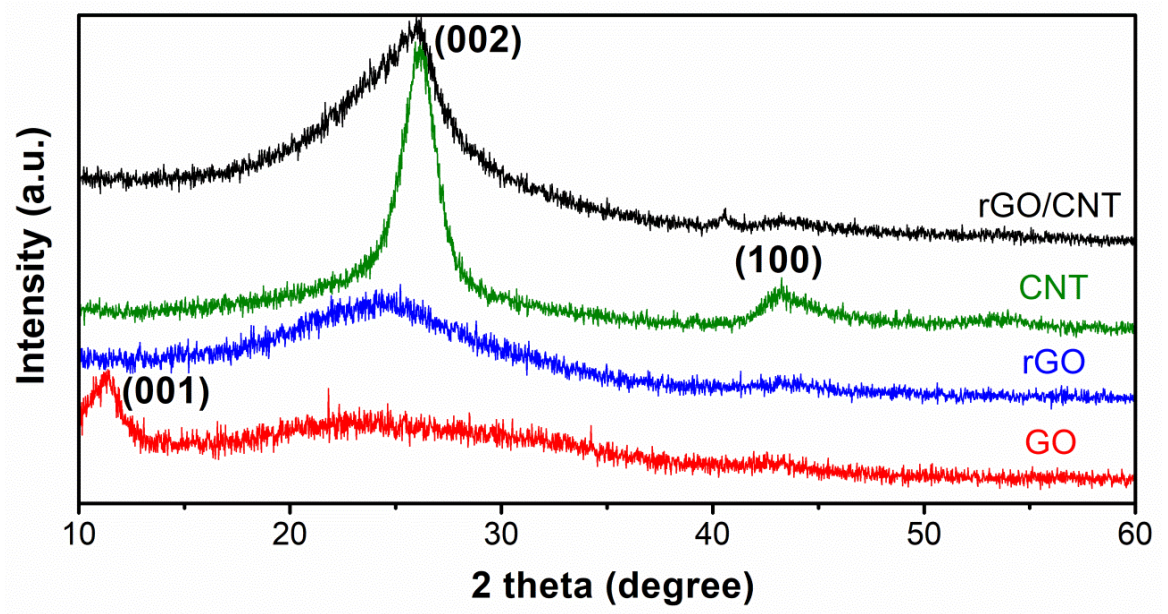

Figure 2. XRD scanned patterns of (a) rGO/CNT paper, (b) CNT, (c) rGO, and (d) GO, respectively. 
The morphology of the hybrid flexible rGO/CNT paper was examined under SEM. Figure 3a shows a tilted view from the cross-section of paper under low magnification. The thickness of the paper is $\approx 12.8 \mu \mathrm{m}$. A uniformly distributed structure of the rGO/CNT layers with micron-sized wrinkles and pores can be observed. Figure $3 \mathrm{~b}$ presents the tilted view of flexible carbon paper at higher magnification. It can be observed that there are CNTs in between rGO sheets to expand the distance of interlayers, which could potentially reduce the chance of rGO sheets stacking and enlarge the distance to facilitate easy diffusion of $\mathrm{Na}^{+}$in the active electrodes.
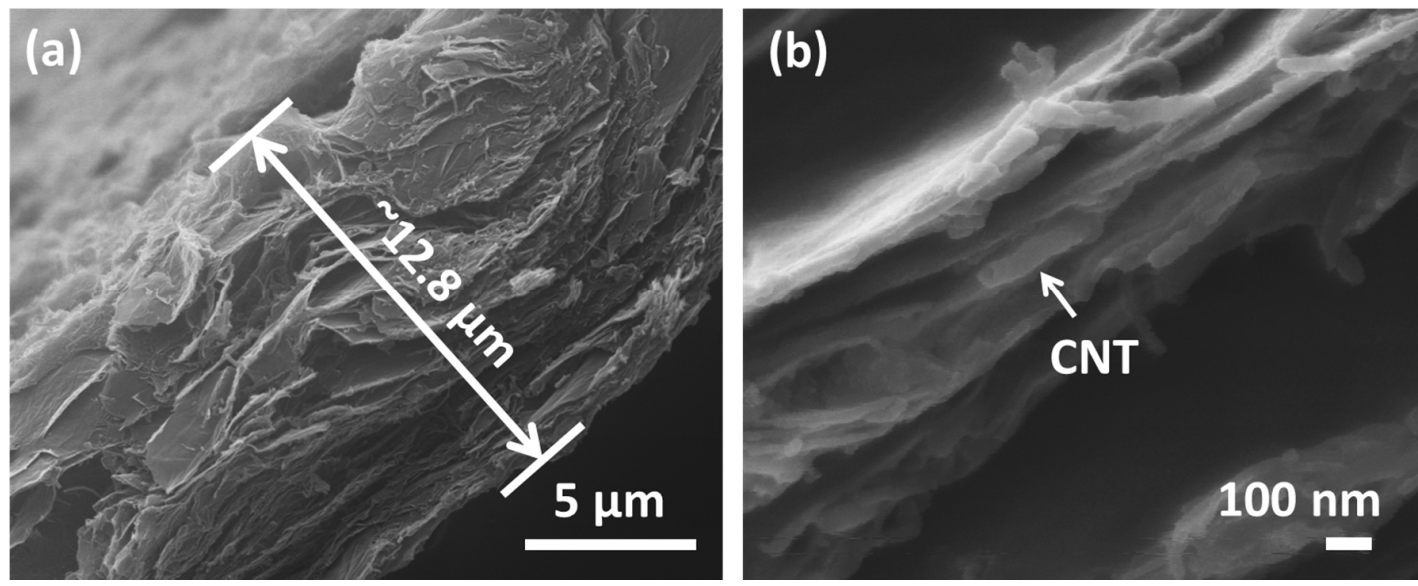

Figure 3. (a,b) SEM images of free-standing $\mathrm{rGO} / \mathrm{CNT}$ paper cross-sectional views in different magnification.

To study the electrochemical performance of free-standing rGO/CNTs paper as anode for NIBs, cyclic voltammetry $(\mathrm{CV})$ was carried out and shows three representative $\mathrm{CV}$ curves of rGO/CNTs paper electrode in the voltage range from 0.001 to $3 \mathrm{~V}$ (vs. Na/ $\mathrm{Na}^{+}$) are presented in Figure $4 \mathrm{a}$. In the first cycle during the cathodic process, one main reduction peak can be observed at $0.42 \mathrm{~V}$ which is mainly due to the decomposition of electrolyte and solid electrolyte interface (SEI) layer formation [29]. This is an irreversible process and the peak disappeared during the subsequent cathodic scan. In the second cycle, a weak reduction peak can be observed at $0.75 \mathrm{~V}$ and assigned to the reaction between sodium ions and the functional groups on the carbon surface [18]. Both weak reduction peaks at approximated $0 \mathrm{~V}$ in the second and third cycle are attributed to the process of $\mathrm{Na}$ ions insertion into the rGO/CNT paper [15]. For the anodic scans, no readily apparent oxidation peaks can be observed, indicating that there is no specific voltage range for $\mathrm{Na}^{+}$extraction from the active rGO/CNTs paper [34]. After the first cycle, the weak peaks and rectangular-shaped CV curves are indicative of a capacitive behavior of sodium storage. Meanwhile, the CV curves are almost overlapping with one the other, indicating acceptable reversibility and stability of free-standing electrode during the processes of $\mathrm{Na}^{+}$insertion and extraction [18].

Figure $4 \mathrm{~b}$ shows the galvanostatic discharge/charge performance of free-standing $\mathrm{rGO} / \mathrm{CNTs}$ paper as NIBs anode at a current rate density of $0.1 \mathrm{~A} \mathrm{~g}^{-1}$. The first cycle of discharge/charge profile delivers initial specific discharge capacity of 1193.4 and charge capacity of $517.1 \mathrm{mAh} \mathrm{g}^{-1}$, respectively. The large loss of irreversible capacity is attributed to electrolyte decomposition as well as SEI layer formation, corresponding to the results of CV evaluation. In following cycles, the rGO/CNT electrode exhibits the sloping discharge/charge profiles. The possible sodium storage mechanism has been discussed from CV curves that the sloping voltage profiles are related to the sodium ion capacitive adsorption on rGO layers $[44,45]$. The majority of the storage capacity comes from the $\mathrm{Na}^{+}$insertion on both surface sides of the rGO layers, which could provide abundant active accommodation sites for fast Na storage [18]. 
(a)

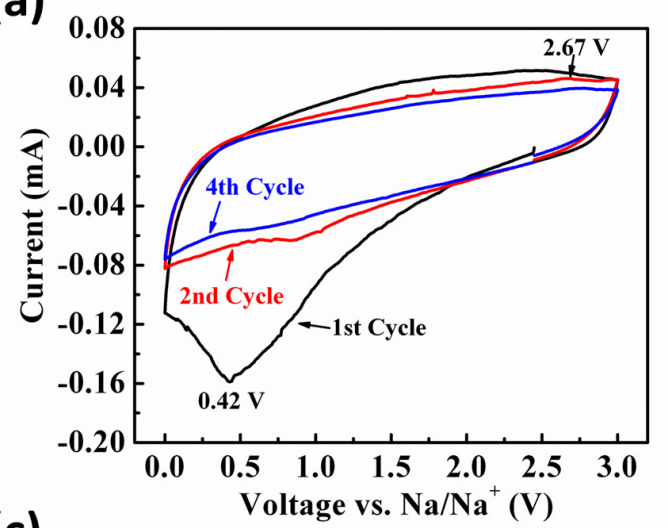

(c)

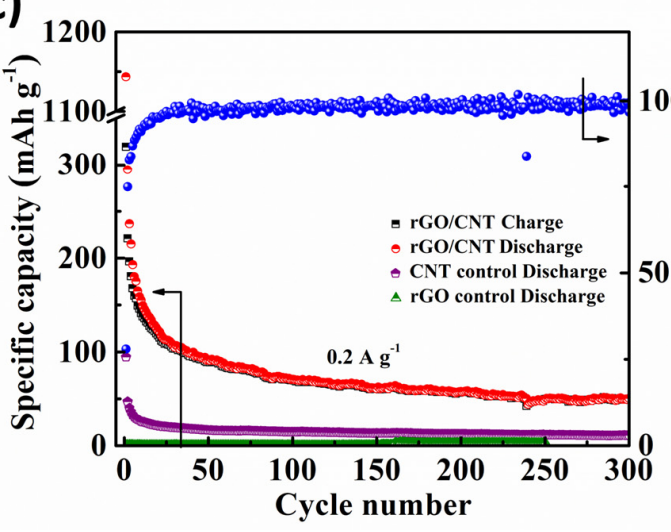

(b)



(d)



Figure 4. Electrochemical evaluation of free-standing rGO/CNT paper (a) Cyclic voltammograms in a voltage window from 0.001 to $3 \mathrm{~V}$ (vs. Na/ $\mathrm{Na}^{+}$) with a scanning rate of $0.1 \mathrm{mV} \mathrm{s}^{-1}$, (b) Discharge/charge curves in the 1st, 2nd and 4th cycles at $0.1 \mathrm{~A} \mathrm{~g}^{-1}$, (c) cycle test results of free-standing $\mathrm{rGO} / \mathrm{CNT}$ paper as well as two control samples rGO and CNT at a current rate of $0.2 \mathrm{~A} \mathrm{~g}^{-1}$ and (d) rate capability at various rates.

Figure $4 \mathrm{c}$ presents the cycling performance of free-standing $\mathrm{rGO} / \mathrm{CNT}$ paper, control samples rGO and CNT at a current rate density of $0.2 \mathrm{~A} \mathrm{~g}^{-1}$. For rGO/CNT paper, there is capacity dropping at the initial $\sim 30$ cycles due to SEI film stabilization process, irreversible reaction process between $\mathrm{Na}^{+}$and surface functional groups and $\mathrm{Na}^{+}$insertion [18]. However, $\mathrm{rGO} / \mathrm{CNT}$ electrode maintains a reversible specific capacity of $49.2 \mathrm{mAh} \mathrm{g}^{-1}$ at 250th cycle, which is higher than the capacity of 11.3 $\mathrm{mAh} \mathrm{g}^{-1}$ for CNT and $2.6 \mathrm{mAh} \mathrm{g}^{-1}$ for rGO. After 30 cycles, coulombic efficiency approaches $100 \%$ and maintains the same at 300th cycle, indicating good capacity retention and cycling stability of the $\mathrm{rGO} / \mathrm{CNT}$ electrodes. Rate capabilities of $\mathrm{rGO} / \mathrm{CNT}$ paper were measured at various current densities to better understand the potential of using as flexible electrodes in NIBs. Figure $4 \mathrm{~d}$ shows that the flexible electrode delivers average discharge capacities of 166.8, 111.3, 90.6, 67.3, 49.5, 31.1 and $9 \mathrm{mAh}$ $\mathrm{g}^{-1}$ at various current rates of 50,100, 200, 500, 1000, 2000 and $5000 \mathrm{~mA} \mathrm{~g}^{-1}$, respectively. After a deep cycling at a relatively high rate of $5000 \mathrm{~mA} \mathrm{~g}^{-1}$, when the density rate resets back to $100 \mathrm{~mA} \mathrm{~g}^{-1}$, the capacitiy can be recovered to $101.4 \mathrm{mAh} \mathrm{g}^{-1}$, indicating a good structural stability of electrode even cycling at a high current density. The interlayer distance of rGO is enlarged by CNT, which could potentially accelerate the transportation of $\mathrm{Na}^{+}$in the hybrid electrode, leading to the enhancement of electrochemical performance. The rate capability performance of $\mathrm{rGO} / \mathrm{CNT}$ paper is comparable to other studies on free-standing graphene anodes [7,46]. An et al. studied free-standing fluorine and nitrogen co-doped graphene paper as anode for flexible sodium-ion batteries [7]. When rate capability was performed at high current density of $1000 \mathrm{~mA} \mathrm{~g}^{-1}$, the electrode delivers a discharge capacity of 50 $\mathrm{mAh} \mathrm{g}^{-1}$ which is pretty much the same as the capacity of our electrode in this work. Also compare to the work from David et al. [46], which is the study of thermally reduced graphene oxide paper as $\mathrm{Na}$ 
storage anodes, our electrode also showed better rate capacities compared to the capacities of $\sim 20 \mathrm{mAh}$ $\mathrm{g}^{-1}$ at high current rate for three types of rGO electrodes. Thus, the high rate capability performance demonstrates that the free-standing $\mathrm{rGO} / \mathrm{CNT}$ paper in this work is a promising anode material for flexible NIBs.

Electrochemical impedance spectroscopy (EIS) measurement was measured on the rGO/CNT electrode before cycle test and after 300 cycles. Figure 5 shows the diameter of the semicircle in high frequency in the Nyquist plots which represents the charge transfer resistance $R_{c t}$. An equivalent circuit in Figure 5 inset is used to fit the Nyquist plots, where $R_{e}$ denotes the electrolyte resistance, $R_{f}$ denotes the interfacial resistance, $R_{c t}$ denotes the charge transfer resistance, $Q_{1}$ and $Q_{2}$ represent related constant phase elements, and $\mathrm{W}$ is the Warburg element [47-49]. From the fitting results, rGO/CNT electrode before cycling exhibits a smaller charge transfer resistance $R_{c t}$ of $12.26 \Omega$ compared to the value of $964.1 \Omega$ after cycling, indicating a higher charge transfer resistance after cycling. This could be due to the relatively higher polarization of sodium ions during cycling [44]. The interfacial resistance $\mathrm{R}_{\mathrm{f}}$ before cycling is $383.5 \Omega$ and shows much higher value of $2985 \Omega$ after cycling, which could be mainly attributed to SEI layer resistance at the surface of electrode materials [50].

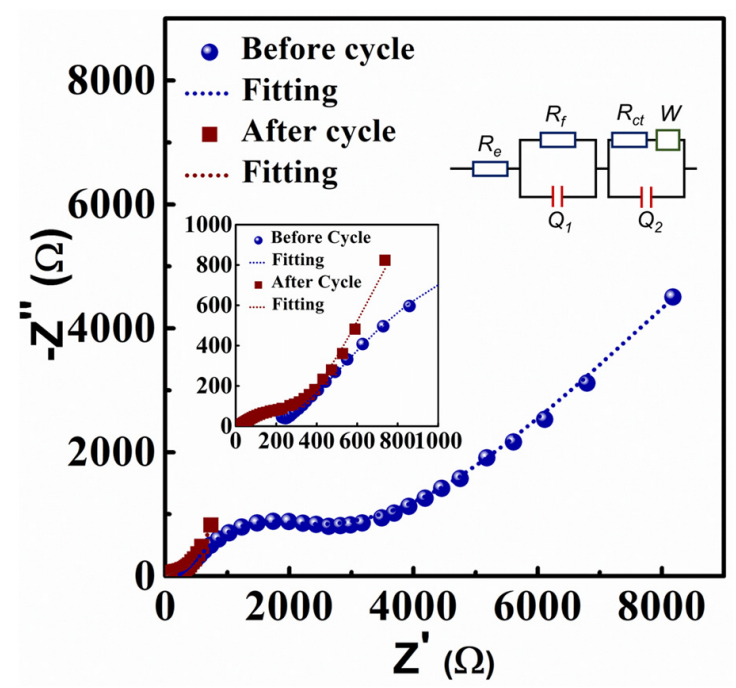

Figure 5. Nyquist plots of free-standing rGO/CNT paper in one Na-ion cell before and after cycle test. The insets show the semicircles in high frequency region and the equivalent circuit diagram used for fitting the Nyquist plots.

\section{Conclusions}

Free-standing and flexible reduced graphene oxide/carbon nanotube papers were successfully synthesized via an electrostatic spray deposition technique and electrochemically evaluated as anode material for flexible NIBs. The free-standing rGO/CNT paper possesses a capacitive charge storage, which contributes the sodium ion storage and stable cyclability. The rGO/CNT paper as flexible anode candidate for NIBs exhibits excellent rate performance with a specific capacity of $101.4 \mathrm{mAh}$ $\mathrm{g}^{-1}$ at the current rate density of $0.1 \mathrm{~A} \mathrm{~g}^{-1}$, even after a high cycling rate of $5 \mathrm{~A} \mathrm{~g}^{-1}$. It can be concluded that the good electrochemical performance of this carbonaceous paper could be ascribed to the expansion of interlayer distance, facilitating transportation of sodium ions. Our study indicates free-standing rGO/CNT paper can be considered as a promising anode candidate for the flexible sodium-ion battery applications.

Author Contributions: Conceptualization, Formal analysis, Data curation, Investigation, writing-Original draft, Y.H.; Conceptualization, Supervision, Funding acquisition, Resources, Writing-Review \& editing, C.W. All authors have read and agreed to the published version of the manuscript.

Funding: This work is partially supported by the National Science Foundation awards (No. 1506640 and No.1509735) and National Science Foundation Paths-Up ERC. 
Acknowledgments: Y.H. gratefully acknowledges experimental support from Amin Rabiei Baboukani and Iman Khakpour.

Conflicts of Interest: The authors declare no conflicts of interest.

\section{References}

1. Etacheri, V.; Marom, R.; Elazari, R.; Salitra, G.; Aurbach, D. Challenges in the development of advanced Li-ion batteries: A review. Energy Environ. Sci. 2011, 4, 3243-3262. [CrossRef]

2. Pan, H.; Hu, Y.-S.; Chen, L. Room-temperature stationary sodium-ion batteries for large-scale electric energy storage. Energy Environ. Sci. 2013, 6, 2338. [CrossRef]

3. Yabuuchi, N.; Kubota, K.; Dahbi, M.; Komaba, S. Research Development on Sodium-Ion Batteries. Chem. Rev. 2014, 114, 11636-11682. [CrossRef]

4. Slater, M.D.; Kim, N.; Lee, E.; Johnson, C.S. Correction: Sodium-Ion Batteries. Adv. Funct. Mater. 2013, 23, 3255. [CrossRef]

5. Wang, L.P.; Yu, L.; Wang, X.; Srinivasan, M.; Xu, Z.J. Recent developments in electrode materials for sodium-ion batteries. J. Mater. Chem. A 2015, 3, 9353-9378. [CrossRef]

6. Liu, H.; Jia, M.; Cao, B.; Chen, R.; Lv, X.; Tang, R.; Wu, F.; Xu, B. Nitrogen-doped carbon/graphene hybrid anode material for sodium-ion batteries with excellent rate capability. J. Power Sources 2016, 319, 195-201. [CrossRef]

7. An, H.; Li, Y.; Gao, Y.; Cao, C.; Han, J.; Feng, Y.; Feng, W. Free-standing fluorine and nitrogen co-doped graphene paper as a high-performance electrode for flexible sodium-ion batteries. Carbon 2017, 116, 338-346. [CrossRef]

8. Kang, H.; Liu, Y.; Cao, K.; Zhao, Y.; Jiao, L.; Wang, Y.; Yuan, H. Update on anode materials for Na-ion batteries. J. Mater. Chem. A 2015, 3, 17899-17913. [CrossRef]

9. Wang, Y.; Kong, D.; Shi, W.; Liu, B.; Sim, G.J.; Ge, Q.; Yang, H.Y. Ice Templated Free-Standing Hierarchically $\mathrm{WS}_{2} / \mathrm{CNT}$-rGO Aerogel for High-Performance Rechargeable Lithium and Sodium Ion Batteries. Adv. Energy Mater. 2016, 6, 1601057. [CrossRef]

10. Wang, X.W.; Guo, H.-P.; Liang, J.; Zhang, J.-F.; Zhang, B.; Wang, J.-Z.; Luo, W.; Liu, H.K.; Dou, S.X. An Integrated Free-Standing Flexible Electrode with Holey-Structured 2D Bimetallic Phosphide Nanosheets for Sodium-Ion Batteries. Adv. Funct. Mater. 2018, 28, 1801016. [CrossRef]

11. David, L.; Bhandavat, L.; Singh, G. $\mathrm{MoS}_{2}$ /graphene composite paper for sodium-ion battery electrodes. ACS Nano 2014, 8, 1759-1770.

12. Xie, X.; Makaryan, T.; Zhao, M.; Van Aken, K.L.; Gogotsi, Y.; Wang, G. MoS 2 Nanosheets Vertically Aligned on Carbon Paper: A Freestanding Electrode for Highly Reversible Sodium-Ion Batteries. Adv. Energy Mater. 2015, 6, 1502161. [CrossRef]

13. Chen, W.; Zhang, X.; Mi, L.; Liu, C.; Zhang, J.; Cui, S.; Feng, X.; Cao, Y.; Shen, C. High-Performance Flexible Freestanding Anode with Hierarchical 3D Carbon-Networks/Fe $\mathrm{S}_{8} /$ Graphene for Applicable Sodium-Ion Batteries. Adv. Mater. 2019, 31, 1806664. [CrossRef]

14. Yan, Y.; Yin, Y.-X.; Guo, Y.; Wan, L.-J. A Sandwich-Like Hierarchically Porous Carbon/Graphene Composite as a High-Performance Anode Material for Sodium-Ion Batteries. Adv. Energy Mater. 2014, 4, 1301584. [CrossRef]

15. Li, X.; Hu, X.; Zhou, L.; Wen, R.; Xu, X.; Chou, S.; Chen, L.; Cao, A.-M.; Dou, S. A S/N-doped high-capacity mesoporous carbon anode for Na-ion batteries. J. Mater. Chem. A 2019, 7, 11976-11984. [CrossRef]

16. Sun, N.; Guan, Y.; Liu, Y.-T.; Zhu, Q.; Shen, J.; Liu, H.; Zhou, S.; Xu, B. Facile synthesis of free-standing, flexible hard carbon anode for high-performance sodium ion batteries using graphene as a multi-functional binder. Carbon 2018, 137, 475-483. [CrossRef]

17. Jin, J.; Shi, Z.-Q.; Wang, C.-Y. Electrochemical Performance of Electrospun carbon nanofibers as free-standing and binder-free anodes for Sodium-Ion and Lithium-Ion Batteries. Electrochim. Acta 2014, 141, 302-310. [CrossRef]

18. Wang, S.; Xia, L.; Yu, L.; Zhang, L.; Wang, H.; Lou, X.W. Free-Standing Nitrogen-Doped Carbon Nanofiber Films: Integrated Electrodes for Sodium-Ion Batteries with Ultralong Cycle Life and Superior Rate Capability. Adv. Energy Mater. 2016, 6, 1502217. [CrossRef] 
19. Xu, J.; Wang, M.; Wickramaratne, N.P.; Jaroniec, M.; Dou, S.X.; Dai, L. High-Performance Sodium Ion Batteries Based on a 3D Anode from Nitrogen-Doped Graphene Foams. Adv. Mater. 2015, 27, 2042-2048. [CrossRef]

20. Kim, S.; Li, X.; Sang, L.; Yun, Y.S.; Nuzzo, R.; Gewirth, A.A.; Braun, P.V. High Energy Density CNT/NaI Composite Cathodes for Sodium-Ion Batteries. Adv. Mater. Interfaces 2018, 5, 1801342. [CrossRef]

21. Xie, X.; Kretschmer, K.; Zhang, J.; Sun, B.; Su, D.; Wang, G. Sn@CNT nanopillars grown perpendicularly on carbon paper: A novel free-standing anode for sodium ion batteries. Nano Energy 2015, 13, 208-217. [CrossRef]

22. Jin, T.; Han, Q.; Jiao, L. Binder-Free Electrodes for Advanced Sodium-Ion Batteries. Adv. Mater. 2019, 32, e1806304. [CrossRef] [PubMed]

23. Zhu, H.; Lee, K.T.; Hitz, G.T.; Han, X.; Li, Y.; Wan, J.; Lacey, S.; Cresce, A.V.W.; Xu, K.; Wachsman, E. Free-standing $\mathrm{Na}_{2 / 3} \mathrm{Fe}_{1 / 2} \mathrm{Mn}_{1 / 2} \mathrm{O}_{2} @$ graphene film for a sodium-ion battery cathode. ACS Appl. Mater. Interfaces 2014, 6, 4242-4247. [CrossRef] [PubMed]

24. Liu, W.; Song, M.-S.; Kong, B.; Cui, Y. Flexible and Stretchable Energy Storage: Recent Advances and Future Perspectives. Adv. Mater. 2016, 29, 1603436. [CrossRef] [PubMed]

25. Tao, T.; Lu, S.; Chen, Y. A Review of Advanced Flexible Lithium-Ion Batteries. Adv. Mater. Technol. 2018, 3 , 1700375. [CrossRef]

26. Wang, H.; Li, W.; Liu, D.; Feng, X.; Wang, J.; Yang, X.; Zhang, X.; Zhu, Y.; Zhang, Y. Flexible Electrodes for Sodium-Ion Batteries: Recent Progress and Perspectives. Adv. Mater. 2017, 29, 1703012. [CrossRef]

27. Xue, J.; Wu, T.; Dai, Y.; Xia, Y. Electrospinning and Electrospun Nanofibers: Methods, Materials, and Applications. Chem. Rev. 2019, 119, 5298-5415. [CrossRef]

28. Li, W.; Zeng, L.; Yang, Z.; Gu, L.; Wang, J.; Liu, X.; Cheng, J.; Yu, Y. Free-standing and binder-free sodium-ion electrodes with ultralong cycle life and high rate performance based on porous carbon nanofibers. Nanoscale 2014, 6, 693-698. [CrossRef]

29. Fu, L.; Tang, K.; Song, K.; Van Aken, P.A.; Yu, Y.; Maier, J. Nitrogen doped porous carbon fibres as anode materials for sodium ion batteries with excellent rate performance. Nanoscale 2014, 6, 1384-1389. [CrossRef]

30. Jin, J.; Yu, B.-J.; Shi, Z.-Q.; Wang, C.-Y.; Chong, C.-B. Lignin-based electrospun carbon nanofibrous webs as free-standing and binder-free electrodes for sodium ion batteries. J. Power Sources 2014, 272, 800-807. [CrossRef]

31. Abouimrane, A.; Compton, O.C.; Amine, K.; Nguyen, S. Non-Annealed Graphene Paper as a Binder-Free Anode for Lithium-Ion Batteries. J. Phys. Chem. C 2010, 114, 12800-12804. [CrossRef]

32. Hao, Y.; Li, X.; Sun, X.; Wang, C. Nitrogen-Doped Graphene Nanosheets/S Composites as Cathode in Room-Temperature Sodium-Sulfur Batteries. ChemistrySelect 2017, 2, 9425-9432. [CrossRef]

33. Ruan, J.; Yuan, T.; Pang, Y.; Luo, S.; Peng, C.; Yang, J.; Zheng, S. Nitrogen and sulfur dual-doped carbon films as flexible free-standing anodes for Li-ion and Na-ion batteries. Carbon 2018, 126, 9-16. [CrossRef]

34. Li, N.; Zhang, L.; Chen, H.; Wang, J.; Ding, L.-X.; Wang, S.; Ashman, P.; Wang, H. Graphene-based nitrogen-doped carbon sandwich nanosheets: A new capacitive process controlled anode material for high-performance sodium-ion batteries. J. Mater. Chem. A 2016, 4, 8630-8635. [CrossRef]

35. Yuan, J.; Chen, C.; Hao, Y.; Zhang, X.; Agrawal, R.; Zhao, W.; Wang, C.; Yu, H.; Zhu, X.; Yu, Y.; et al. Fabrication of three-dimensional porous $\mathrm{ZnMn}_{2} \mathrm{O}_{4}$ thin films on $\mathrm{Ni}$ foams through electrostatic spray deposition for high-performance lithium-ion battery anodes. J. Alloy. Compd. 2017, 696, 1174-1179. [CrossRef]

36. Yuan, J.; Chen, C.; Hao, Y.; Zhang, X.; Gao, S.; Agrawal, R.; Wang, C.; Xiong, Z.; Yu, H.; Xie, Y. A facile synthetic strategy to three-dimensional porous $\mathrm{ZnCo}_{2} \mathrm{O}_{4}$ thin films on $\mathrm{Ni}$ foams for high-performance lithium-ion battery anodes. J. Electroanal. Chem. 2017, 787, 158-162. [CrossRef]

37. Li, X.; Wang, C. Engineering nanostructured anodes via electrostatic spray deposition for high performance lithium ion battery application. J. Mater. Chem. A 2013, 1, 165-182. [CrossRef]

38. Zhu, C.; Fu, Y.; Yu, Y. Designed Nanoarchitectures by Electrostatic Spray Deposition for Energy Storage. Adv. Mater. 2018, 31, 1803408. [CrossRef]

39. Beidaghi, M.; Wang, C. Micro-Supercapacitors Based on Interdigital Electrodes of Reduced Graphene Oxide and Carbon Nanotube Composites with Ultrahigh Power Handling Performance. Adv. Funct. Mater. 2012, 22, 4501-4510. [CrossRef]

40. Adelowo, E.; Baboukani, A.R.; Chen, C.; Wang, C. Electrostatically Sprayed Reduced Graphene Oxide-Carbon Nanotubes Electrodes for Lithium-Ion Capacitors. C-J. Carbon Res. 2018, 4, 31. [CrossRef] 
41. Manickam, S.; Muthoosamy, K.; Bai, R.G.; Abubakar, I.B.; Sudheer, S.M.; Hongngee, L.; Hwei-San, L.; Nayming, H.; Chia, C.H.; Lim, H.N.; et al. Exceedingly biocompatible and thin-layered reduced graphene oxide nanosheets using an eco-friendly mushroom extract strategy. Int. J. Nanomed. 2015, 10, 1505-1519. [CrossRef]

42. Mishra, S.K.; Tripathi, S.N.; Choudhary, V.; Gupta, B. Surface Plasmon Resonance-Based Fiber Optic Methane Gas Sensor Utilizing Graphene-Carbon Nanotubes-Poly(Methyl Methacrylate) Hybrid Nanocomposite. Plasmon 2015, 10, 1147-1157. [CrossRef]

43. Wang, K.; Pang, J.; Li, L.; Zhou, S.; Li, Y.; Zhang, T. Synthesis of hydrophobic carbon nanotubes/reduced graphene oxide composite films by flash light irradiation. Front. Chem. Sci. Eng. 2018, 12, 376-382. [CrossRef]

44. Ali, G.; Mehmood, A.; Ha, H.Y.; Kim, J.; Chung, K.Y. Reduced graphene oxide as a stable and high-capacity cathode material for Na-ion batteries. Sci. Rep. 2017, 7, 40910. [CrossRef] [PubMed]

45. Luo, Z.; Zhou, J.; Cao, X.; Liu, S.; Cai, Y.; Wang, L.; Pan, A.; Liang, S. Graphene oxide templated nitrogen-doped carbon nanosheets with superior rate capability for sodium ion batteries. Carbon 2017, 122, 82-91. [CrossRef]

46. David, L.; Singh, G. Reduced Graphene Oxide Paper Electrode: Opposing Effect of Thermal Annealing on Li and Na Cyclability. J. Phys. Chem. C 2014, 118, 28401-28408. [CrossRef]

47. Hu, L.; Shang, C.; Huang, L.; Wang, X.; Zhou, G. $\mathrm{Cu}_{3}$ Ge coated by nitrogen-doped carbon nanorods as advanced sodium-ion battery anodes. Ionics 2019, 26, 719-726. [CrossRef]

48. Shang, C.; Hu, L.; Fu, L.; Huang, L.; Xue, B.; Wang, X.; Shui, L.; Zhou, G. Improving lithium storage capability of ternary Sn-based sulfides by enhancing inactive/active element ratio. Solid State Ionics 2019, 337, 47-55. [CrossRef]

49. Shang, C.; Hu, L.; Lin, Q.; Fu, X.; Wang, X.; Zhou, G. Integration of $\mathrm{NaV}_{6} \mathrm{O}_{15} \cdot \mathrm{nH}_{2} \mathrm{O}$ nanowires and $\mathrm{rGO}$ as cathode materials for efficient sodium storage. Appl. Surf. Sci. 2019, 494, 458-464. [CrossRef]

50. Hao, Y.; Chen, C.; Yang, X.; Xiao, G.; Zou, B.; Yang, J.; Wang, C. Studies on intrinsic phase-dependent electrochemical properties of MnS nanocrystals as anodes for lithium-ion batteries. J. Power Sources 2017, 338, 9-16. [CrossRef]

Sample Availability: Samples of the compounds are not available from the authors.

(C) 2020 by the authors. Licensee MDPI, Basel, Switzerland. This article is an open access article distributed under the terms and conditions of the Creative Commons Attribution (CC BY) license (http://creativecommons.org/licenses/by/4.0/). 